\title{
Implementation of "Education for Sustainability" in Three Elementary Schools - What can we Learn about a Change Process?
}

\author{
Shirley Miedijensky ${ }^{1,2^{*}}$, Anat Abramovich ${ }^{3}$ \\ ${ }^{1}$ Oranim Academic College, Tivon, ISRAEL \\ 2 Shamir Research Institute, Haifa University, Haifa, ISRAEL \\ ${ }^{2}$ Israeli Center for Scientific and Technological Education, Technion, Haifa, ISRAEL
}

Received 4 August 2018 - Revised 10 December 2018 - Accepted 13 December 2018

\begin{abstract}
This study examines the process of educational change as demonstrated in three elementary schools implementing education for sustainability (EfS). Actions and stages in the change process were characterized. Data included interviews with the school principals and teachers involved, in-school observations, and documentation (schools' vision statements, websites, and reports). Our findings indicate that important factors for a successful implementation include motives for change, persons involved, actions carried out, and follow-up activity. While all three schools showed evidence of changes implementing EfS as a regular part of the school's philosophy, only one school demonstrated changes deemed permanent and significant. This was the only school that implemented a gradual and structured process of change, that executed many actions at each stage, and where the principal and staff were well-qualified and fully committed. This study contributes to understanding how changes may be implemented in educational systems and emphasizes the importance of each stage.
\end{abstract}

Keywords: educational change, education for sustainability, environmental education

\section{INTRODUCTION}

One major challenge of modern society is to find a balanced relationship between humans and nature. Education for sustainable development (ESD) or education for sustainability (EfS) can help ensure humankind's future existence (Didham \& Ofei-Manu, 2018; Jickling \& Wals, 2008; Loughland, Reid, Walker \& Petocz, 2003; Stevenson, 2006). In the literature, there is a debate on the different nuances between ESD and EfS. Some feel that the term EfS is more appropriate since it focuses more on social justice whereas ESD implies a focus on development and economics (Common \& Stagl, 2005; Sauvé, 2005). Others refer to both terms equally, and consider them both to be education that deal with environmental issues from broad scope of aspects, such as social justice, environmental activism based on rational decisions, and so forth (Abramovich \& Loria, 2015, Didham \& Ofei-Manu, 2018; Jickling $\&$ Wals, 2008). In this research, we use the term EfS to be all encompassing. In recent years, Israel has demonstrated significant progress in implementing EfS at the national level, and the Israeli Ministry of Education, in conjunction with the Ministry of Environmental Protection, promote such education in schools. One of the significant steps taken by these departments is the transformation of educational institutions into 'green' educational institutions (Sagy \& Tal, 2015; Tal \& Peled, 2017). Nevertheless, despite the steps taken in Israel in recent years towards enhancing EfS, some claim that implementing environmental education in schools is challenging due to a number of factors: there is no structured, compulsory curriculum; there is a scarcity of appropriate study materials; and there is a shortage of qualified teachers (Abramovich \& Loria, 2015; Negev, Sagy, Garb, Salzberg \& Tal, 2008; Tal \& Abramovich, 2013; Tal \& Peled, 2017). Most importantly, the absence of a clear, unified, vision means that environmental education cannot realize its full potential since each educator contributes according to their own personal perceptions and the actions they are individually familiar with (Sagy \& Tal, 2015; Tal \& Abramovich, 2013; Tal \& Peled, 2017).

(C) 2019 by the authors; licensee Modestum Ltd., UK. This article is an open access article distributed under the terms and conditions of the Creative Commons Attribution License (http://creativecommons.org/licenses/by/4.0/). \shirley_m@oranim.ac.il (*Correspondence) \anat.abramovitch@gmail.com 


\section{Contribution of this paper to the literature}

- Optimal change requires a formal curriculum that puts sustainability at its core, provides appropriate professional development for teachers, ensures daily management in school, and includes self-checks and evaluation.

- The success of introducing a change into schools depends on a number of factors, including the motives for the change, the role players involved in the implementation process, the specific actions carried out, and what steps, if any, are taken to improve the change process in the future.

- A successful change process demands the implementation of all stages of the process with no steps skipped.

Implementing EfS in schools relies upon educational leadership and is essentially a process of change. A successful change process requires the organization to implement steps that include clarifying the rationale behind the desired change, reducing the uncertainty that often accompanies a change process, and recruiting suitable staff (Abramovich \& Loria, 2015; Fullan, 2008). Furthermore, for change to be effective, it must be gradual, and comprise four major stages: initiation (planning), implementation (actual activities and protocols), institutionalization (the change becomes an integral part of the organization), and outcome (focusing on the results to improve the process in the future) (Fullan, 2007).

A study by Tal, Mintz, and Amir (2015) of the integration of EfS into the education system in Israel pointed out that how the changes were implemented was never examined, and because it is difficult to track the effectiveness of EfS programs in terms of changes in knowledge, attitudes, and behaviour, they suggested that the effectiveness of the program might be better determined by examining documentation concerning the change processes. Our study, therefore, aimed to focus on the process of change itself in three elementary schools and to examine, in depth, characteristics and complexity of the process, and identify key factors influencing the implementation and outcome of the change.

In line with this goal, our research questions were the following:

1) What factors influence the process of change in the schools?

2) What were the characteristics of the stages of change in the schools?

\section{THEORETICAL BACKGROUND}

\section{Environmental Education and EfS around the World and in Israel}

The term 'environmental education' emerged toward the end of the 1960s (Stapp et al., 1969) and generally refers to any act of education (within or without the school) that aims to impart knowledge about the physical and human environment; promote care and respect for the environment, one's fellow humans, and society; and teach skills for working for the betterment of both the natural environment and human society (Tal, 2016).

Beginning in the 1980s, an important redirection occurred regarding environmental education when it began to be universally regarded as interdisciplinary. In the 1990s, focus moved to the concept of 'sustainability', that is to say, thinking about how actions today (in particular, concerning the environment) will affect future generations (Tilbury, 1995). 'Sustainability' has thus been deemed the path along which the world needs to tread, even though each country is responsible for defining its own appropriate path (Sauvé, 2005).

Defining the term 'sustainability' led to the definition of the concept of 'EfS' and the question of whether environmental education and EfS have the same educational objectives - education for the purpose of well-being through the wise use of resources - or if they are two different approaches in terms of philosophy and execution. Sauvé (2005) differentiated between older trends based on human-environment relations and newer trends, which incorporate values of democracy, civil cooperation, and social values. In her viewpoint, EfS includes elements of environmental education and is thus the modern face of environmental education. In this paper, the terms EfS and environmental education are used interchangeably, as they both infer the intelligent application of the subject while exercising discretion to safeguard resources.

In Israel, environmental education remained on the side-lines until 2000. Up until then, education initiatives were only on the local level. However, with the international awakening to the subject, the Israeli Ministry of Education and the Ministry of Environmental Protection embraced the topic and initiated actions that, among other things, included an outline for an EfS program in the schools (Sagi \& Tal, 2015; Tal, 2016; Tal \& Abramovich, 2013).

In recent years, there has been initiation of a program towards educational institutions accreditation as 'green schools' (Sagy \& Tal, 2015), that is, schools that offer unique programs in environmental issues, provide activities that encourage the sensible use and reduced consumption of resources, and cultivate and promote environmental projects in the community - all according to values defined by the Ministry of Environmental Protection. In 
addition, special environmental studies programs for high schools have been designed, and several of them are included in the matriculation exams.

Yet, the complexity of the definition of environmental education, a subject that comprises elements from many disciplines, can lead to a large gap between 'intention' and 'practice' regarding all that concerns teaching environmental issues (Sanera, 1998).

Some difficulties associated with teaching environmental science may lie with the pedagogical staff, some of whom lack motivation and enthusiasm, due to their lack of knowledge or skill in this area or due to a lack of a supportive, positive attitude in the school (Ernest, 2007; Tal \& Abramovich, 2013).

Another major difficulty with EfS is that most schools focus on teaching the scientific aspects while overlooking those crucial aspects that lead to developing critical thinking, taking a stand, and expressing emotions and experiences - all crucial for developing a relationship and affinity to environmental issues (Tsevreni, 2011). Others argue that because EfS is embedded within such a wide variety of subjects, it tends to lose its substance (Bonnet \& Williams, 1998; Negev et al., 2008; Tal \& Abramovich, 2013), leading students to believe that global problems are so widespread and complex and that they (the students) cannot possibly have any worldwide influence. Consequently, they lose any interest in the subject.

Recognizing the limitations mentioned above, the Ministry of Education and the Ministry of Environmental Protection strongly support the development and enactment of environmental education programs throughout the educational system (beginning in pre-school and extending through elementary school and into junior high) (Sagi \& Tal, 2015; Spektor-Levy \& Abramovich, 2015; Tal \& Abramovich, 2013).

Nevertheless, even given the best intentions of all involved and adequate resources and staff, the complexity of the subject means that genuine environmental education and EfS cannot be successfully implemented into schools unless an appropriate and properly applied process of change is introduced into the system. For this reason, we elected to observe the process of change (with respect to introducing EfS) in three Israeli elementary schools and determine if a 'proper' process of change could be linked with the successful introduction of the EFS program.

\section{The Process of Implementing Changes in Education}

Change means forsaking old routines and attachments to acquire new, hopefully better, ones (Hargreaves, 2002, 2009). Educational change aims to develop and improve the school or institution and its teachers' professionalism to upgrade the education given to their students. However, change is never easy and introducing a change in an educational institution, given the number of stakeholders involved (including those who dictate the curriculum) is especially difficult. A principle who wants to introduce a change into his or her school needs to understand that people, resources, and multiple considerations must be taken into account, and, moreover, change takes time. True change is never an isolated event (Anderson, 2010) and the initiators of change must recognise that "the interface between individual and collective meaning and action in everyday situations is where change stands or falls" (Fullan, 2007, p. 9).

Novel projects and programs and revolutionary reforms aimed at improving the education system are proposed almost daily. Implementing new concepts into an educational organization is challenging because processes and technical aspects required for the introduction of said changes may be undermined by inhibiting factors such as poor leadership among those who are meant to institute the change, poor or deficient resources, or role players who do not fully understand the reasons and methods for applying the proposed change (Fullan, 2006, 2008; Hargreaves, 2010). In actual practice, change can be a complex, non-algorithmic process, and the stakeholders instituting the change must take this into account (Fullan, 2008).

Change is usually a complex process that occur in stages over time. Rogers (1995) noted that members of an educational organization experience five major stages during the implementation of a change: developing awareness, developing interest, commenting, trial, and adoption.

There are various models that describe the actual change process in educational systems. One model is the 'Comprehensive Innovation' model, where comprehensive changes are introduced into an organization's culture based on second-degree changes (Sarason, 1995). This approach is centralized: policy makers have an overall view of the system and introduce innovations using a 'top down' approach (Argyris \& Schon, 1978; Raz, 2006). Another common model is termed 'Islands of Innovation'. Here the change is introduced for one specific content area or task, and changes take place in small 'islands' within the organization with the objective being that these changes (first degree changes) will serve as models for change in other areas, eventually leading to overall innovation within the entire organization (Sarason, 1995). This model presents a less threatening way to introduce change, since it is initially specific to one characteristic or behaviour, with no (initial) influence on the overall organizational culture in terms of norms and basic assumptions. In this model, change is driven either 'top down' or 'bottom up' depending on which particular group in the organization (usually those who are 'passionate' about the venture) initiates the change (Avidov-Ungar, 2010). 
A third model for implementing change in an educational system is Fullan's model (Fullan, 2007). This model has four key stages: initiation, implementation, institutionalization, and outcomes. Since our study is based on Fullan's model, we shall discuss these stages in greater detail below.

1) Initiation. Plans for all the elements of the change and its implementation are drawn up, including an appropriate organizational framework and a sound strategy. Any questions or dilemmas that come to mind are discussed, such as the scale (large or small) of the change, the estimated length of time for introducing it, and whether school personnel are qualified to introduce it on their own or require help from outside experts.

2) Implementation. The school's educational vision is developed and the team established. In this stage, the organization may find that some (or even all) teachers object to or have difficulty with introducing the change, and decisions need to be made how to overcome such obstacles. Factors affecting the success of this stage include the characteristics of the change (need, quality, efficiency, complexity, clarity), local factors (district, community, principal, teachers), and external factors (governmental and external agents).

3) Institutionalization. At this integral and consistent part of the school's daily operation, and the factors influencing point, steps are taken to make the change an the change are internal. They include expanding the vision, planning further developments, empowering teachers to take initiative, consolidating resources, and solving problems. Further changes may be introduced, requiring renewed planning processes.

4) Outcomes. In the final stage, the achievements are critically analysed and the predefined criteria scrutinised. Thought is given to how the process of change may be improved, expanded, and reinforced over time.

\section{Factors Affecting the Success of the Change}

Implementing an educational change is a complex process and it is crucial to understand all the factors required for success. Formerly, school principals were the main instigators of change; today, other role players in the school may initiate changes in their areas of responsibility (Fullan, 2007). However, no matter who initiates the change, it is not enough to simply control the change; one must know how to guide it.

First, it is important that the change initiators act as role models so that 'change' transcends a mere slogan and becomes real and concrete innovation. Next, the plan for change needs to be flexible enough to adjust the implementation process to suit the organizational structure (Carter, 2008; Fullan, 2007; Levin, 2010). Because there is often a large gap between the principal's perception of the change (a way to improve the institution's image) and the teachers' (a way to improve the image of the principal), teachers and other role players need to be led to understand the rationale behind the change.

Successful change is gradual and requires a continuous effort of all the participants in all stages of the process (Carter, 2008; Fullan, 2007; Levin, 2010), who should be focused on improving and developing educational processes and not merely on the structure of the change for accountability purposes (Levin \& Fullan, 2008).

Preparing the staff and other role players for what is to be expected will reduce any uncertainties they may have. They should be encouraged to initiate, modernize, change, and streamline the process (Fullan, 2007; Oplatka, 2015) while given time to adapt and be encouragement to focus on results and successes and analysing reasons for any failures. New skills will be strengthened through continuous practice and constructive feedback. In-school and external technical, administrative and psychological support will be made available as needed. The leaders will apply pressure as required and encourage interaction between role players (Fullan, 2007).

Fullan (2007) offered some important insights that leaders should take into account when initiating change: understanding that theories of education and theories of change complement each other, paying full attention to conflicts and variances, understanding the significance of the functions required in a situation in which the organization may be approaching chaos, and realizing that there is no one solution to any one problem.

In summary, effective change needs the following: a leadership that is focused on the change, sets clear goals, and has high expectations; a flexible organizational structure that allows self-evaluation so as to make necessary further adjustments; a supportive atmosphere; continuous professional development for school members; and the involvement and support of parents and the community.

\section{METHOD}

\section{Research Environment}

We were interested in schools which had independently chosen to implement EfS in their activities, which we felt would indicate a genuine desire for change. In order to reduce variables related to budget and resources, we approached three socio-economically similar public elementary (grades 1-6) schools who initiated the relevant activities demanded by the Ministry of Education and the Ministry of Environmental Protection and requested 
consent from the principals and pedagogic staff for the study. The schools (henceforth labelled S1, S2, S3) had 218, 320 , and 450 pupils, respectively.

\section{Research Approach}

This qualitative study was conducted as a series of case studies observing the individual and organizational behaviours and processes in each school. This type of study allows intensively analysing the processes, critically observing the personal and social actions and interactions of the role players under diverse circumstances, and determining the extent of durability of the changes (Yin, 2012).

Our goal was to examine the implementation process over all its stages so as to understand in depth the processes that occurred in each school.

\section{Data Collection}

Data was obtained via interviews, observation, and documentation.

Interviews. In order to gain a deeper understanding of the change process, in depth, 60-to-90-minute interviews were conducted with the principals and four teachers from each school. The teachers taught science or EfS-related subjects and were selected by purposeful sampling (Cresswell \& Plano Clark, 2011). All the respondents expressed willingness to reflectively express their experiences and opinions regarding the changes that had been initiated in their school to implement environmental education. The interviews were scheduled in advance and carried out in a place convenient for the respondents.

Interview questions concerned the teachers' conception of EfS, their opinion regarding the necessity, process, and opposition to (of any) of introducing EfS into their school, how opposition was confronted, and their opinion of whether the implementation was successful (See Appendix).

Observation. The researchers visited all the school several times to observe the actions carried out within the framework of environmental education and whether changes were sustained. Observations regarding the physical environment within the school buildings (classes, corridors, etc.) and in the schoolyard were photographed and noted in writing (The use of photographic images was and is in accordance with ethical guidelines and respect for the individual.)

Documentation. The researchers also collected internal and external documents attesting to the implementation process in the schools. Internal documents included meeting protocols, messages sent between the role players, evidence of the school's vision and goals, follow-up from the Green Council regarding recycling collections, certificates of recognition for classes that exhibited excellence in the topic, and documentation regarding the certification (or not) of the school as a green school. External documents included follow-up reports sent to representative of the Ministry of Environmental Protection, local press reports, and information from the school's Internet site.

The three instruments described above allowed data triangulation so as to be able to identify any relationship between respondents' statements, observations in the field, and data collected from documents.

Requisite standards of ethical conduct in research were complied with throughout the study, especially with respect to informed consent of respondents and basic codes of ethics (maintaining bidirectional communication, extended commitment of researchers, and full confidentiality with respect to participants and schools, Marshall \& Rossman, 2014).

\section{Data Analysis}

Data were analysed in two stages. First, an inductive analysis of data was performed for preliminary identification of categories and criteria for each. Thematic coding of the categories (Braun \& Clarke, 2006) led to the identification of four core ones: motives for implementing change, involvement in the implementation process, actions performed in the school, and ways to improve the process. Second, we characterized the phase of change (see Figure 1) that each school was in and quantified the investment each school made at each stage of change.

In order to establish credibility, five researchers independently coded the categories and compared findings. Initial agreement was $85 \%$. The researchers conducted a discussion and recoded their findings, resulting in total agreement with respect to category nomenclature and $92.1 \%$ agreement regarding analysis of the changes at each school. 


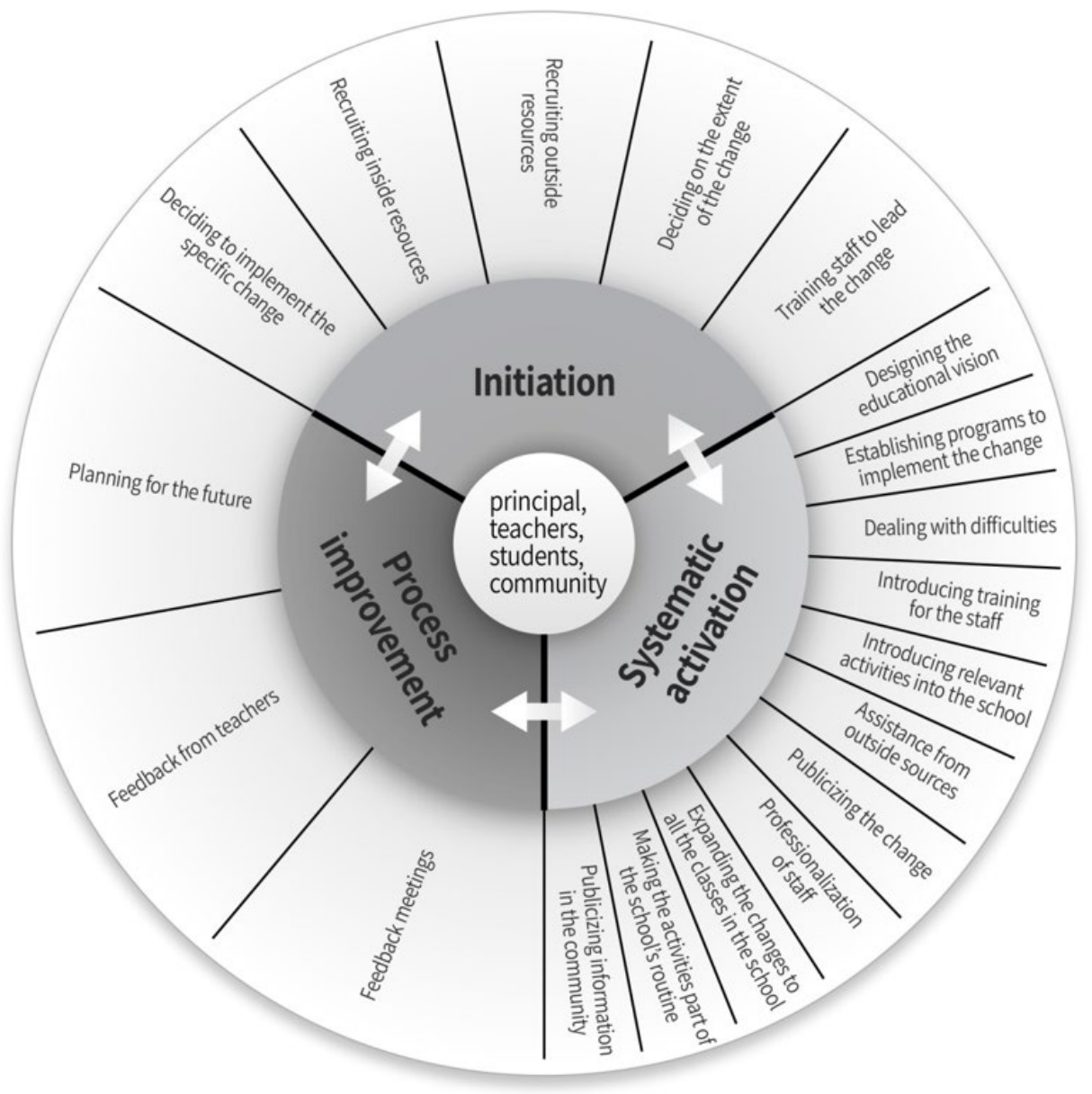

Figure 1. Stages and components of change

\section{Model of Change}

Figure 1 illustrates the model of change used in our research. The core comprises the main participants: educational staff (teachers and administrators), students, and community (including parents). We believe that all participants play some part at every stage of implementation.

The next ring comprises the stages themselves. Our model is based on Fullan's model (Fullan, 2007), nevertheless, while his model has four stages - initiation, implementation, institutionalization, and outcome, our model has only three stages - initiation, systematic (routine) activation, and process improvement. That is to say, for the purpose of this study, Fullan's implementation and institutionalization stages were merged into our 'systematic activation' stage. In our opinion, merging these activities expresses the implementation process in schools more accurately, especially as we felt that certain actions could not be precisely attributed to one or the other of Fullan's stages. For example, all the schools introduced relevant activities, but only schools S2 and S3 publicized information in the local community. However, we were not sure at that point whether this was part of the schools' routine (institutionalization stage) or still part of the implementation stage. The relevant components for each stage were identified based on Fullan's (2007) (see theoretical section) and on an inductive analysis of the collected data (see Figure 1).

For example, the systematic activation phase includes eleven possible components (actions): the first seven designing the educational vision, establishing programs to implement the change, dealing with difficulties that arise, initiating staff training, introducing relevant activities into the school, recruiting experts to help expand the project to the entire community (e.g., assistance by external factors), and publicizing the change - are followed by professionalization of the staff, expansion of the change to all classes in the school, establishing the new activities as part of the school's routine, and publicizing information in the community.

All stages were weighted equally. The initiation phase is basic and must be thorough and in-depth (Fullan, 2007), but each individual step or combinations of steps are extremely important in understanding overall implementation. 
The components for the other two stages (systematic activation and process improvement) can be seen in the Figure 1.

\section{RESULTS}

\section{Factors Influencing the Process and Results of Change in Schools}

Four key factors that influence the change process were identified: a) motives for the change, b) role players involved in the implementation process, c) actions carried out in the school to promote EfS, and d) steps taken for improving the change process.

\section{Motives for change}

The motives behind the introduction of EfS were different for all three schools. In S3, the principal was searching for a means to improve the school situation:

The school was in bad shape! I had to make a change to brand, improve, and distinguish it. I publicized and marketed a new curriculum that looked interesting and comprehensive, with a large number of diverse subjects/courses. I believed that branding our school as a 'green school' would attract more students and improve its reputation (Principal, S3).

In S2, EfS was introduced following the local authority's demand that all schools obtain green certification. One of the teachers noted: 'The change was initiated by the local council's requirement... It was their idea, not ours. It was not something the school needed or someone in the school wanted to direct' (Teacher [T], S2).

In S1, the principal initiated the change through a desire to connect the school to the natural environment in which it is located:

It was obvious to me that we wanted a change and it was important to have some unique 'banner' behind which to stand to guide this change. Look at the geographic setting of our school and the nature of the surrounding communities! I knew that our 'banner' had to involve sustainability! (Principal, S1).

The documentation of all three schools revealed that each considered environmental education to be an important value. In fact, the school vision (SV) of each mentions EfS goals and targets. The SV of S3, for example, offers a detailed description of EfS in their curriculum: 'The school shall develop pedagogic knowledge by providing tools for creative and critical thinking, while instilling environmental values and knowledge that emphasize the environment and the community' (SV, S3).

The SV of S2 was more general: 'The school shall underscore environmental values in its teaching and operate in light of such values' (SV, S2).

The SV of S1 referred to the principal's goal of linking environmental education, the community, and the geographical setting: 'Our school, in partnership with the community, will develop a green culture that is in keeping with the geographical character of our region, and which will constitute an integral part of our education for human and environmental values' (SV, S1). However, interviews with S1 teachers indicate that they believed the motives for the change were for branding purpose only and not due to a belief in such a need:

Only a very small number of staff at the school chose to implement the change because they actually believed in it! Maybe some of them follow such practices at home, but I believe others did it just for show. It was introduced so that there would be something to show visitors, to mimic what happens in other schools (T, S1).

\section{Role players in the implementation process}

Four major role players were identified as being influential in the change process: the school principal, the science teachers, the parents, and the Green Council. While all three principals claimed that they had initiated the change, the teachers' statements suggest that only in S3 was the principal the main agent of change who consistently led the process throughout the stages: 'The principal was the main agent of change, our anchor. She pushed, initiated, believed, and did not let up for a minute - even till today. She was the driving force in environmental issues and it influenced us' (T, S3).

In S1 and S2, the principals both presented themselves as being the main agents of change. For example, the principal of S2 said that he initiated the project in response to the demands of the council to work toward the green 


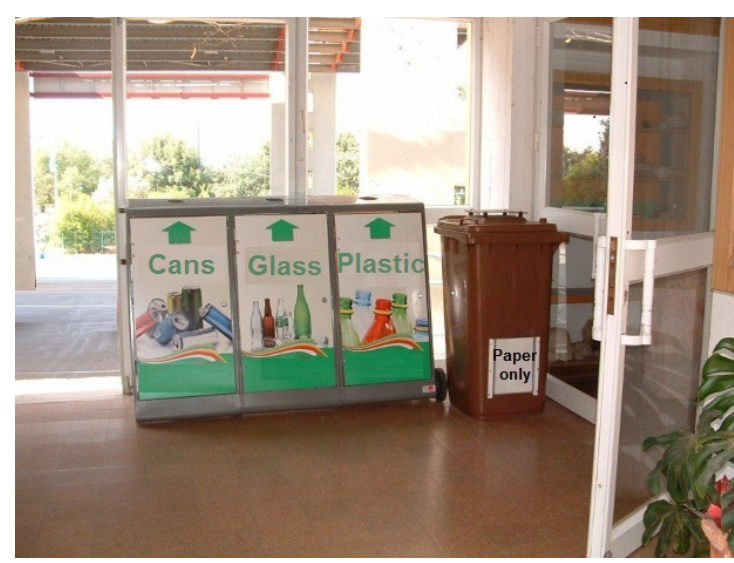

Picture 1. Recycling station in S3

certificate, but appointed a teacher to take responsibility since he was busy with other projects: 'I appointed the science teacher to run the Green Certificate project. I was not really involved in it. At the moment, I am promoting the subject of IT, which, to my mind, is unique' (PS2). In S1, the principal also stated that she initiated the change then transferred dayto-day operation to a team:

I initiated the project and led it at the onset since I am the school leader and was pushing the staff to apply for a Green Certificate. I did not give up even though they claimed we were not green enough. I thought this would motivate them to do other things ( $\mathrm{P}, \mathrm{S} 1)$

However, interviews with S1 and S2 teachers indicate that they did not consider the principals significant agents of change. For example, 'The principal did not seem to care enough. She simply sent out messages with clichés, slogans, or demands by email. This is not enough!' (T, S1). And from S2: 'Except for dividing us into working groups during a staff meeting, I don't see that he [the principal] did anything significant. He really had no influence, no initiative. Any initiative came from individual teachers who cared' (T, S2).

Regarding parental involvement, parents were actively involved in schools S3 and S2 and were clearly agents of change. In fact, one of the parents in S3 was known to be passionate about the subject, and initiated some projects and even encouraged the principal:

A father with 'passion' really gave life to the project. He pushed the principal, went with us to professional development. He never let up. He went with us everywhere. Only someone who really cares can drive something like this, and he is one of those people (T, S3).

No indication of parent involvement came up in the interviews with S1 teachers, despite the school's vision regarding the importance of cooperation with the community.

Both the S1 and S2 principals stated that the responsibility for introducing EfS to the school was given to the teams of science teachers and the Green Council: 'The Green [Student] Council were responsible for gathering resources and explaining the issues. And, of course, the science teachers' (P, S2); and 'Last year, a Green Council was established that basically was responsible for the entire subject. It consists of student representatives from each grade and a science teacher' $(\mathrm{P}$, $\mathrm{S} 1)$. However, none of the interviews with $\mathrm{S} 1$ teachers made any mention of the Green Council's role in the project; any reference to its role in implementing change was found solely in the document submitted to obtain the green certificate: 'At the beginning of the academic year, the school established a Green Council with representatives from grades five and six. Its role was to help introducing green culture and initiate environmental projects throughout the year'.

\section{Actions taken to introduce environmental education}

The study included observing and documenting the appearance of the school's physical space, especially classrooms and schoolyards, for evidence of actions introduced into the schools during the implementation process. The nine key actions described below were identified.

(1) Reduction and reuse of resources. In all three schools, garbage cans were distributed and recycling stations set up to collect paper and batteries. S1 and S2 each had only a single bin for each material, and these were not situated centrally. In S3, bins to collect reusable or recyclable waste (beverage containers, paper, clothes, organic waste for compost) were placed in every classroom, along with to two large recycling stations in two central locations in the school, as can be seen in Picture 1. 


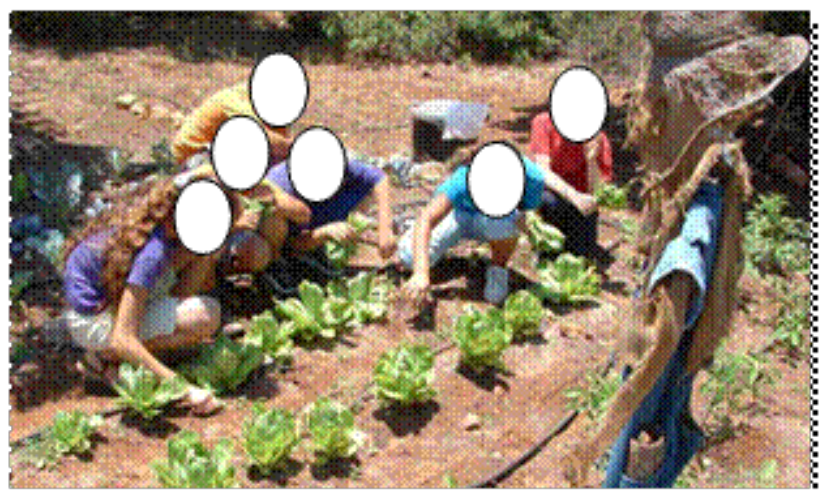

Picture 2. An organic garden outside the classroom in S1

S3 also demonstrated a number of other environmentally friendly actions. For example, we observed solar energy cells on the roof of the school. The principal related to this issue as well: 'The local council leases the roof of our school [and produces electricity]. Although the electricity belongs to them, we take advantage of the educational benefit of having children experience a caring community trying to conserve energy' $(\mathrm{P}, \mathrm{S} 3)$. Also, recycling was very evident. We noted that materials used in the learning environments as well as for much of the school decorations were recycled. The topic was highlighted in interviews with the principal and teachers: 'Notice that our report cards are printed on recycled paper. It is important that the management provide an example' ( $\mathrm{T}, \mathrm{S} 3)$.

(2) Cleanliness and care of the school. Our observations of S3 revealed a school that was clean and well-cared both within and without. Even the smallest corner was designed to bestow environmental values and to make use of recycled materials. The classrooms and schoolyard of S2 were also clean and well-cared for. In S1, however, nicely decorated and well-cared-for areas existed alongside areas where trash had been tossed or school property was neglected or in poor repair. For example, several scientific installations had been set up in the yard, but most didn't work and some were even broken. The schoolyard has grassy and pebbled areas, and plastic bags and empty snack wrappers were scattered over the pebbled area.

(3) Learning environment. As part of the study, we examined (through both observation and interviews) the schools' internal and external learning environments. S3 presented rich and varied learning environments pertaining to environmental education throughout: all the classrooms, the corridors, and the schoolyard.

The design of the doors in school S3 was especially noteworthy. Each had been designed to look like a tree native to the immediate environment, and each one was unique. They had been created by the children in collaboration with an artist hired for the purpose. Through this project, the pupils learned about the value and their attachment to the environment. One teacher explained:

\begin{abstract}
The doors you see at the entrance to the classrooms were my initiative. It was important that the entrances to the classrooms convey environmental values. A door serves as a barrier between interior and exterior, and my intention here was that there should be a connection. Today, the pupils understand the relationship between inside and outside, between man and nature. We are an inseparable part of it. They worked with an artist. It was an in-depth, valuable, and very major project in the school. $(\mathrm{T}, \mathrm{S} 3)$
\end{abstract}

We did not observe any area specifically dedicated to environmental education in S2, whereas two such areas were observed in S1: a board in one of the classrooms, and an organic garden outside the classroom (see Picture 2).

(4) Application for Green Certification. 'Green schools' are educational institutions that receive financial support from the Ministry of Environmental Protection to help purchase resources and finance activities to promote environmental education. To be awarded this status, schools must present a detailed plan according to criteria published on the Ministry's website and if it meets specific criteria, a ministerial committee awards the school a Green Certificate. All three schools had submitted plans to obtain a Green Certificate.

(5) Establishment of a Green Council. The Green Council typically included a representative from each class and science teachers, who were responsible for the activity of the council. In all three schools, interviews attested to the establishment of a Green Council, but field observations and documents attesting to the actions of the Council were found only in the case of S3.

(6) Activity days and undertakings to promote environmental education. In S2 and S1, evidence was found regarding special environmental activity days or other one-time activities to promote environmental education and awareness. 
The Green Council initiated activities in school, especially entire days that focused on environmental education. For example, one day we held a 'Green Fair'. Signs were posted in several places. There were presentations, films, art activities. Bottles were collected for recycling. There were other activities, too. But this was a one-time event; it did not repeat throughout the year. $(\mathrm{T}, \mathrm{S} 2)$

In S3, the environmental activities mentioned by the interviewees were long-term and held regularly throughout the year.

(7) Integrating environmental education content into the general school curriculum. In S3, it was prominently apparent that environmental education had become a central axis of the curriculum. Unique programs that included EfS had been designed for all the classes, and EfS activities were held regularly throughout the year - both within the school and outside it. In S2 and S1, a few teachers stated that they incorporate environmental education in their classes, but there was no evidence of an organized curriculum for the entire school, except those lessons specified in the documents submitted to obtain the Green Certificate.

(8) Community projects. As part of the requirements for the Green Certificate, schools are obligated to initiate community projects. S3 mentioned five ongoing environmental projects taking place within the school's community. S2 had organized one community project. None of the respondents in S1 mentioned any community project; the only evidence for such was what had been written in the documents prepared for the Green Certificate.

(9) Publicizing school activities in the community. S3 seemed to be the only school that publicized the school's activities in environmental education. The principal stated that she invested much effort in publicizing and branding her school to the parents and the community in order to recruit them into the process, secure their involvement and support, and reduce any opposition.

\section{Improving the change process}

During interviews, respondents were asked if and how they would change the process of implementing environmental education. Their suggestions were analysed to provide another perspective on the changes that took place in the schools.

In S3, the principal stated how important it was to maintain 'the spirit' of environmental education. She emphasize that she hired only teachers who exhibited enthusiasm. In addition, she said how important it was to constantly initiate new projects to ensure that environmental education be an integral part of the activity and a familiar language in the school:

I recommend continuing specialization in this field. To come up with other ways to inspire the team. To visit other schools - we did this a lot; it gave us lots of new ideas. The team needs to brainstorm how to raise this project even more. Equally important is for it to become part of the everyday language in the school (P, S3).

The S2 principal said that choosing the right staff- people excited about the topic and with a spark in their eyes - is the main way to improve and raise environmental education in the school. The principal also said that it is important to empower teachers who come up with ideas on the subject and give them a suitable platform to accomplish those ideas.

I think the success of a project (or not) depends on whether the people who lead it are suitable. When I introduce into the school projects that excite me, such as the IT and music programs, things really take off... If I can find teachers willing to do these things not only for their home, but for the school, too, it would be successful!

It is important to lead the process properly, to begin with a united team. The best thing is to have someone passionate about the idea to lead the team, someone who will get others hooked. It is important that the team be part of the decision-making process and that they are doing it because they feel the need for it, not because it is being enforced (P, S2).

In S1, teachers pointed out that improving the process would depend first and foremost on the principal becoming a central figure leading the change. They also mentioned the importance of offering the team professional development, making the change gradually and systematically, and ensuring that the entire team are partners in change and it does not become the province of only a few individuals. One of the teachers recommended the following: 
Table 1. Number of references to the actions in each stage for each school

\begin{tabular}{cccc}
\hline School & Initiation stage & Systematic activation stage & Process Improvement stage \\
\hline S1 & 2 & 64 & - \\
\hline S2 & 2 & 58 & - \\
\hline S3 & 25 & 68 & 5 \\
\hline
\end{tabular}

Introducing a change needs to be done gradually and systematically. First, the subject should be introduced to the staff, to inspire and unite them. Then, a small team with the ability to lead the change should be chosen. They need to be experts. They should undergo professional development and then later share their knowledge with the rest of the staff. At the same time, the principal must take the lead! To be at the forefront! To sweep the staff along after her, and sometimes to be assertive if someone doesn't cooperate. It is important that everyone understands that this is not a project that belongs only to a few individual teachers (T, S1).

\section{Characteristics of the Stages of Change in the Various Schools}

In this section, we present the stages of implementation on a case-by-case basis. As mentioned before, the change process had three stages: initiation, systematic activation, and process improvement.

Data collected from interviews, documents, and observations were quantified to clearly indicate how much each school invested in each of the stages. This was done by counting the number of statements regarding actions at each stage of the process. Initiation stage actions took place before the change was introduced; systematic activation stage actions were done to implement the change and integrate it into the system; process improvement stage actions were those used to test results, improve criteria, or plan ahead.

We examined how many of the possible actions for each stage were mentioned. (Recall from Figure 1 that there are five actions in initiation, eleven for systematic activation, and three for process improvement). Table 1 shows the number of actions mentioned for each school and for each stage. It is clear that the systematic activation stage yielded the most references in each school.

\section{School S1}

Initiation. The administration carried out only two initiation actions: incorporating the concept of environmental education into the school's vision and designing a school logo to reflect this concept (an 'inside resources').

It [the change] came more from the top than from the field. We tried to introduce this to the staff already last year and focused on it when we worked on the school's vision. Even our logo was designed in the spirit of 'green' (P, S1).

Systematic activation. Most of the actions occurred at this stage and included organizing activity days devoted to resource conservation and cleaning up the environment. Despite the significance of this stage, teachers' statements indicate that only a few teaching staff actively participated in these actions:

Very few participated in this venture. We were a small team that dealt with the subject in meetings. I was a partner, but in fact I didn't have the time, and I didn't do much. If you really want to get things moving to initiate a real change, one must devote time to do it with the pupils. It is important to see what happens out in nature and not only to post pictures on the walls and notice boards (T, S1).

Another criticism was that the actions were not implemented properly to become routine:

[We told the students] not to come with plastic bags. We introduced the idea of bringing food only in plastic boxes and even distributed a box to every student. But this turned out to be just a slogan and was never followed through! There was a lot of hubbub, but in practice, it didn't work. It wasn't successful (T, S1).

Process improvement: Nothing was mentioned.

In summary, S1 implemented only two stages of the change process (see Figure 2): initiation (two actions out of a possible five listed were taken: deciding to implement the specific change, and recruiting inside resources) and systematic activation (two out of eleven possible actions: establishing programs to implement the change and introducing relevant activities into the school). 


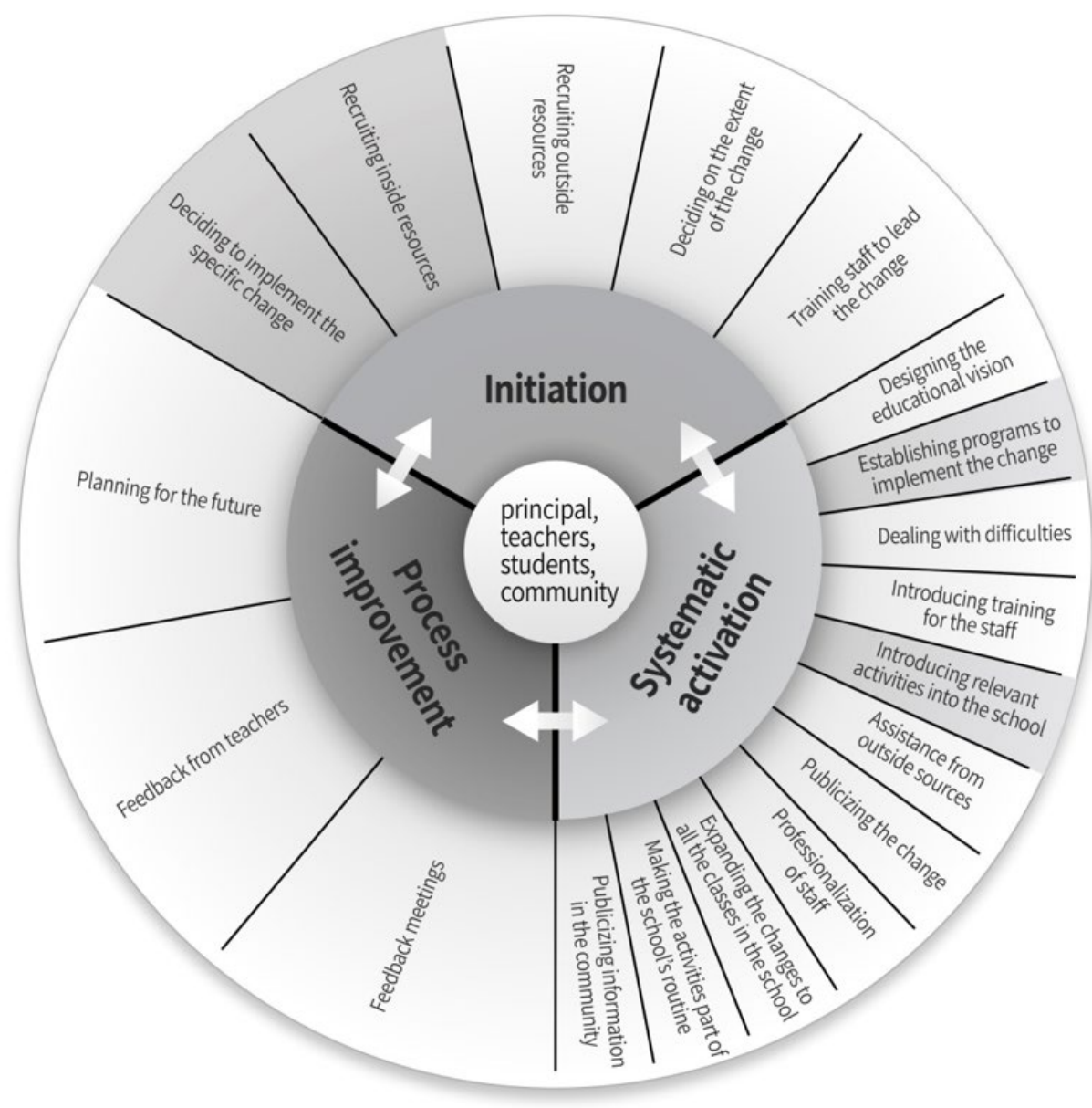

Figure 2. Stages and components of change in S1

\title{
School S2
}

Initiation. There was very little evidence of planning before actually initiating the change. In the interviews, the teachers complained of not being involved at all in the planning process:

\begin{abstract}
Most of the staff were not involved properly in the initiation. It was the province of the science teacher only; the other teachers received no guidance or training and the staff members didn't share in the process. Many of us were completely out of the picture and had no idea what was being planned. There was no significant leader for the process. It was an enforced change. We did not see its necessity $(\mathrm{T}, \mathrm{S} 2)$.
\end{abstract}

Systematic activation. A number of actions were performed, as one teacher described: 'There were many activities in the school. We were involved with recycling and watched films about the subject. We also had other activities related to the environment' (T, S2).

Other statements indicate that efforts were taken to incorporate the subject and to implement it as part of the usual school routine. For example, the Green Council met once a week. The principal also spoke about the establishment of a parents' committee to upgrade the façade of the school:
A committee of parents were given the task to make the façade of the school more aesthetic, inviting, and relaxing. This really got the parents involved. They even painted the columns. One parent took it upon himself to refurbish the sports hall. Some parents had the task of pointing out hazards inside and outside the school (P, S2).

However, the principal's statement criticizes the process and attests to the scarcity of activities at this stage: 'We did the bare minimum! There was no continuity. The teacher in charge did not get the project moving. We missed recruiting parents as a substantial resource. We did not make it something significant in the school.' 


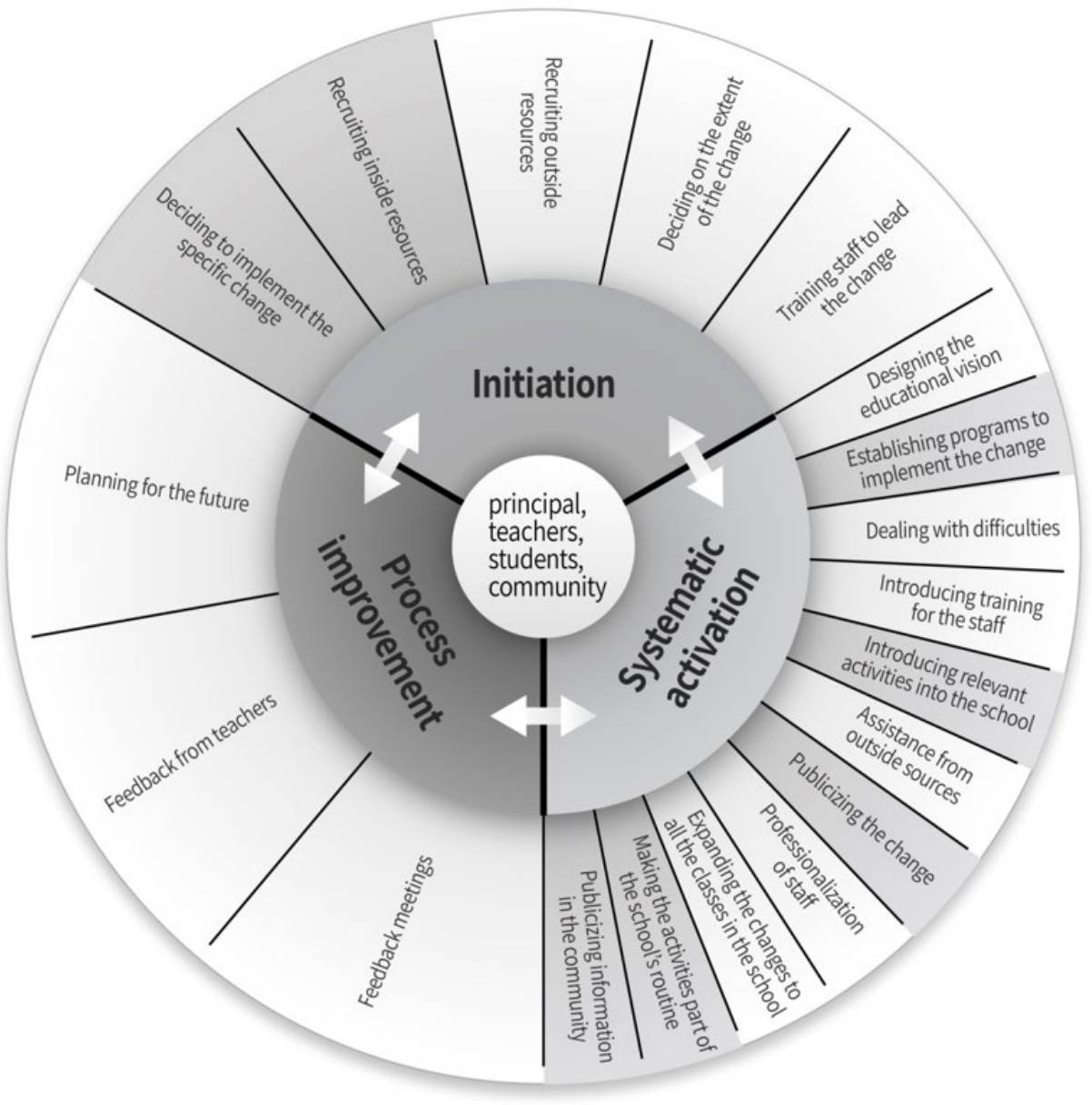

Figure 3. Stages and components of change in S2

Process improvement: None mentioned.

In summary, similar to S1, in S2 only two stages of the change process were implemented (see Figure 3): initiation and systematic activation. In the initiation stage two actions of the five listed were taken: deciding to implement the specific change and recruiting inside resources. In the systematic activation stage, five of the eleven possible actions were taken: establishing programs to implement the change, introducing relevant activities into the school, publicizing the change, making the activities part of the school's routing, and publicizing information in the community.

\section{School S3}

Initiation. A significant number (approximately one third) of statements referred to actions carried out during this stage. These included preparing a statement of intention, discussing tactics, mapping resources, mobilizing people, training teachers, and making plans for introducing the change. The meticulous attention paid to this stage and the actions taken can be seen in the principal's statement:

We started out by discussing our statement of intention, wherein we stated exactly what our goals were. We mapped all the resources available in the immediate vicinity, in the community, and from the Ministry of Education. We formed a plan indicating what changes we wanted each year. We tried to get accepted as an experimental school, but we weren't successful. However, the process kept us focused on what steps we needed to take (P, S3).

Systematic activation. At this stage, a comprehensive process for implementing changes was undertaken that included many actions: designing the learning environment throughout the school by reusing and recycling materials; establishing a number of recycling centres; designing unique curricula for all the classes; recruiting parents to take part in school activities; eliciting cooperation with outside agencies such as the Society for the Protection of Nature, local authorities, and the agricultural farm located adjacent to the school. 


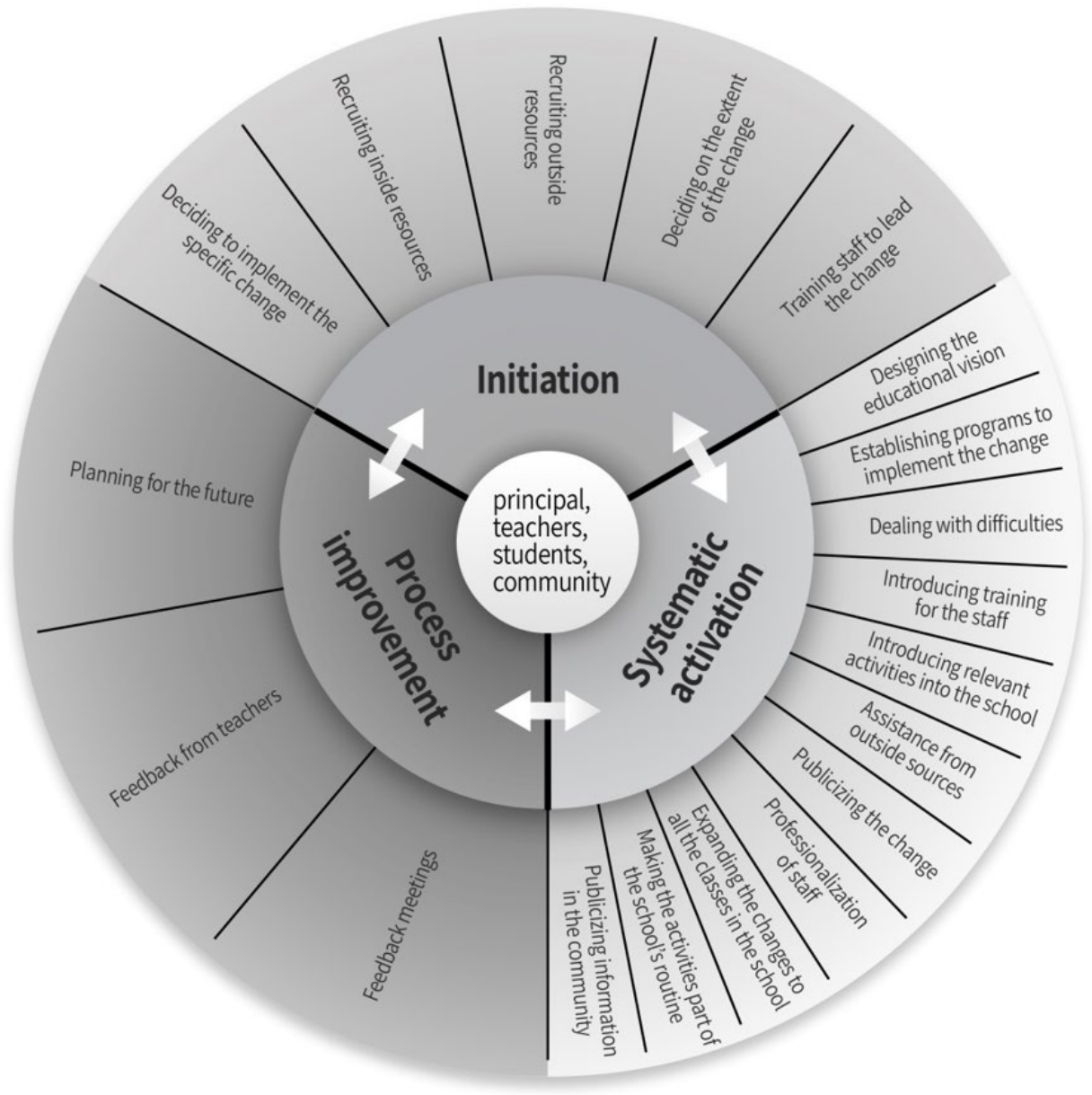

Figure 4. Stages and components of change in S3

From the statements of the teachers, it is clear that the staff were involved in the process. The art teacher, for example, stated: 'All the staff were actively involved. We were all committed to the process. Without it we could not have made such a difference in the school. We all wanted it to be successful!' (T, S3).

Notes in a follow-up Green Council notebook describes the results of a program to collect soft-drink bottles for recycling: 'One thousand bottles and one bag-full of papers [special 50-litre collection bags] were collected. In first place grade 5-B with 284 bottles, second place - grade 2-C with 255 bottles, third place - grade 1-C with 111 bottles' (Follow-Up note, Green Council, S3).

Other evidence points to implementation of the change as a way of life in the school and this includes the introduction of monthly field trips, dynamic recycling centres, daily clean-up duty monitors, research projects, an active Green Council, taking newspapers for recycling, permanent learning programs, integrating arts, activities with animals, participation in national conferences, and additional professional development of teachers.

There are pupils who are in charge of picking up trash. We have lovely spaces that are well tended. In this sense, we have been successful because our pupils won't see a mess and say, 'I didn't do it', but will do something about it. The food for the animals is collected by kids at home or at the agricultural farm (P, S3).

Another example of the extent of EfS implementation is the vast assortments of projects that pupils made from reused materials. The school is a showcase for art based in reusing and recycling materials such as bottle caps and biodegradable materials. Their works are displayed throughout the school in the various learning centres.

Process improvement. We noted that the Green Council (already from the beginning of the implementation process) held annual meetings to review activities, brainstorm, and plan ahead. In addition, teachers documented extra-classroom activities, allowing the Green Council to learn and progress from the information.

In summary, S3 implemented all the stages of change (see Figure 4): initiation, actualization, and outcome and took all possible actions. 


\section{DISCUSSION}

Our findings indicate that successfully introducing a change into schools depends on a number of factors, including the motives for the change, the role players involved in the implementation process, the specific actions carried out, especially if done in a systematic way, and what steps, if any, are taken to improve the change process in the future.

In all three schools, at least some of the respondents stated that the science teacher and the Green Council were the internal agents of change for the implementation process. However, this was only substantiated by physical evidence and in all the interviews in S3. In S1 and S2, the science teachers stated that they were the agents of change, yet the statements of the other respondents did not corroborate this, and findings in the field indicated that these teachers had not, in fact, constituted a significant factor in the change process.

In S3, the parents were involved in the process and were a significant factor in initiating and encouraging the change. As mentioned, one parent with initiative and vision became an important agent for change in the school, certainly contributing to the success of the process. In S2, there was a partially successful attempt to involve parents, but in S1, no parents were involved. While this may not be a reason for failure, parent involvement can certainly be cited as an advantage (Chawla \& Cushing, 2007; Tal, 2004).

In S3, the change was driven by an enthusiastic principal who believed that implementing environmental education would advance her school and who made EfS a central pillar in the school's makeup and a stepping-off point for its growth in other areas. Furthermore, and probably most importantly, in S3, the change was introduced gradually and systematically, and the full complement of actions was performed throughout the three stages of implementation. It is evident that the entire staff were active participants and underwent professional training. Training and professional development for the staff are an integral part of dealing with the developments and challenges that can take place during the change process and have a significant effect on the success of its implementation (Cummings \&Worley, 2014; Fullan, 2007).

In S2 and S1, however, the changes were not made gradually and systematically. Hardly any initiation-stage actions took place. The majority of actions took place in the systematic activation stage, and these were only localized, thus minimally affecting the general activity of the school. Furthermore, the principals in these schools were not a significant factor in the implementation of EfS, and the teachers and parents participated only to a small degree. It is clear from our observations that the change processes in S1 and S2 were only partial at best.

It is evident that not enough was invested in the initiation stage in S1 and S2, and this was probably a major reason for failure to successfully implement the change. In fact, Oplatka (2015) argues that if the initiation stage is neglected, the action and institutionalization of the change (the "systematic activation" stage in this study) will be inefficient. Also according to Oplatka, it is important that the school address the issue of the length of the initiation phase and decide whether hired external factors are required to implement the change. They must also decide just how much change is actually required. If preliminary issues are not sufficiently dealt with, they will arise anew during the systematic activation stage, making the implementation difficult.

Another factor for this failure may be attributed to the fact that the principal's rationale behind the change was unclear, and the staff were not recruited to help benefit from whatever rationale was involved. Staff collaboration is a very crucial part of the process (Cummings \&Worley, 2014), and if the staff do not clearly understand the underlying rationale and feel that the project is the province of only a few individual staff members (Fullan, 2007; Oplatka, 2005), they will not feel inspired to contribute to its success. Furthermore, in S1 and S2, the staff were not given suitable training, another reason for them not being properly motivated and often feeling uncertain and helpless. These factors can hinder implementation (Carter, 2008; Ernst, 2007; Fullan, 2006, 2008; Hargreaves, 2010; Levin, 2010; Tal \& Peled, 2017).

It is also important to understand that sometimes there is a contradiction between the principal's concept of change and that of the teachers, and therefore it is crucial to properly deal with the initiation step in the change process (Aas, 2017; Fullan, 2007).

Another aspect that emerged from the study involves the actions carried out by the schools as part of their Green Certification process. These actions, while important, are only the first step in promoting consistent environmental education in the schools. This was demonstrated by the observations we made in schools S1 and S2: although EfS was introduced into the schools, it was not enough to ensure its successful and comprehensive implementation. This indicates the importance of additional steps, the most important of which, as we have already noted, being the gradual systematic introduction of the change. More specifically, it is necessary to note the scope of implementation and the direction of its development (Avidov-Ungar, 2010). In addition, the "directives" of the Ministry of Education are not sufficient. Effective change requires a focused leader, clear targets, high expectations, appropriate academic knowledge, and the ability of the school to give itself honest feedback. All this must take place in a supportive atmosphere and with the recruitment and integration of the community (Fullan, 2007). 
Furthermore, systematic activation of the change greatly depends on the teachers' degree of commitment and their belief that change is indeed necessary to improve their work. Change will become embedded over time only when there are clear plans and development processes that are able to deal with any problems and challenges that the school might confront (Oplatka, 2015).

There are other factors to consider (these were not directly addressed in this study). Even if actions during the systematic activation stage are all-encompassing and meaningful, the implementation of change might not be successful if there is a lack of financial support by outside parties or if key staff members leave the school (Fullan, 2007). That being the case, optimal change requires a formal curriculum that puts sustainability at its core, provides appropriate professional development for teachers, ensures daily management in school, and includes self-checks and evaluation. Furthermore, and as mentioned before, the active involvement of parents, teachers, and students is also a key factor in the optimal implementation of change (Abramovich \& Loria, 2015). This is apart from the crucial central role that the principal has as the leader in the process of change (Fullan, 2007).

In this paper, we presented a process of change that was implemented over a period of time during which those involved (principal, teaching staff, teachers, students, and parents) remained present throughout the process. The question is how to preserve the change over time without being dependent on these individuals. How does it become an integral part of the school's routine?

As mentioned above, the plan developed by the Ministry of Education in cooperation with the Ministry of Environmental Protection for implementing EfS into the school system involves training at least $80 \%$ of the teachers and preparing a school curriculum in which the principles of sustainability are taught in at least four subjects and on at least three grade levels. In addition, schools are supposed to receive assistance in the implementation process. Given such a program, the successful implementation of EfS will not have to depend on those human factors that constituted an integral part of the program implementation in the schools studied. However, no studies to date have substantiated or disproven this claim. Tal (2016) believes that a professional committee of academic EfS experts from the Ministry of Education is a necessity, as is the need for an ongoing series of professional development courses for teachers. We tend to agree with Tal and, in light of our findings herein, believe that this issue needs to be considered.

Our study indicates that a successful change process demands the implementation of all stages of the process with no steps skipped. Furthermore, because of the dynamics of the process, a "checkpoint" date (e.g., end of year) should be set when the process is reviewed and recommendations for improvement made.

In light of the findings of this study, we suggest the following: 1) The principal's involvement cannot be overemphasized. He or she is the one who must ensure cooperation with the authorities, liaise with other schools, and create a motivated and enthusiastic leadership team in the school. 2) A comprehensive program must be prepared in the initiation phase that defines the planned change(s), gives specific steps for recruiting and training leadership staff, and outlines initial plans. 3) A means to evaluate the systematic activation phase needs to be developed to allow the school to make any necessary adjustments improvements. 4) The local authority should be involved in funding schools in its jurisdiction. This will allow expanding the project in the initiation and the systematic activation stages. 5) Finally, the parents' involvement should be encouraged throughout the process of implementing environmental education, beginning with the initiation stage. Environmental awareness is not something that is restricted to the school. Many actions related to environmental education take place in the students' homes, making the parents' partnership in the process crucial.

The model described in this article can be used as a scaffold for change in the educational system. However, it should be noted that although the current article points to the effectiveness of this tool, additional studies to test its reliability under different conditions and for different programs of change are warranted.

\section{REFERENCES}

Aas, M. (2017). Understanding leadership and change in schools: expansive learning and tensions. International Journal of Leadership in Education, 20, 278-296.

Abramovich, A., \& Loria, Y. (2015). The Long-Term Impact of an Education for Sustainability Course on Israeli Science \& Technology Teachers' Pro-Environment Awareness, Commitment and Behaviour. The Australian Journal of Environmental Education, 31(2), 1-16. https:/ / doi.org/10.1017/ aee.2015.31

Anderson, S. E. (2010). Moving change: Evolutionary perspectives on educational change. In A. Hargreaves, A. Lieberman, M. Fullan, \& Hopkins (Eds.). Second International Handbook of educational change (pp. 65-84). New York: Springer. https:/ / doi.org/10.1007/978-90-481-2660-6_4

Argyris, C., \& Schon, D. A. (1978). Organizational learning: a theory of action perspective. Reading, Mass: Addison Wesley. 
Avidov-Ungar, O. (2010). "Islands of innovations" or "comprehensive Innovation." Assimilating educational technology in teaching, learning, and management: a case study of school networks in Israel. Interdisciplinary Journal of E-Learning and Learning Objects, 6, 259-280. https:/ / doi.org/10.28945/1314

Bonnet, M., \& Williams, J. (1998). Environmental education and primary children's attitudes towards nature and the environment. Cambridge Journal of Education, 28, 173-159. https:/ / doi.org/10.1080/0305764980280202

Braun, V., \& Clarke, V. (2006). Using thematic analysis in psychology. Qualitative Research in Psychology, 3, 77-101. https://doi.org/10.1191/1478088706qp063oa

Carter, E. (2008). Successful change requires more than change management. The Journal for Quality E Participation, $31,20-23$.

Chawal, L., \& Cushing, D. F. (2007). Education for strategic environmental behaviour. Environmental Education Research, 13(4), 437-452. https:/ / doi.org/10.1080/13504620701581539

Common, M., \& Stagl, S. (2005). Ecological economics. An introduction. New-York: Cambridge University Press. https:// doi.org/10.1017/CBO9780511805547

Cresswell, J. W., \& Plano Clark, V. L. (2011). Designing and conducting mixed methods research. 2nd Thousand Oaks, CA: Sage.

Cummings, T. G., \& Worley, C. G. (2014). Organization development and change. Stamford, CT: Cengage Learning

Didham, R. J., \& Ofei-Manu, P. (2018). Advancing policy to achieve quality education for sustainable development. In Leicht, A., Heiss, J., Byun, \& W.J. (Eds.). (2018). Issues and trends in Education for Sustainable Development. Paris: United Nations Educational, Scientific and Cultural Organization

Ernst, J. (2007). Factors associated with k-12 teachers' use of environment-based education. Environmental Education Research, 3, 15-32. https:/ / doi.org/10.3200/JOEE.38.3.15-32

Fullan, M. (2006). The future of educational change: system thinkers in action. Journal of Educational Change, 7, 113122. https://doi.org/10.1007/s10833-006-9003-9

Fullan, M. (2007). The new meaning of educational change, $4^{\text {th }}$ edition, New York: Teachers College Press.

Fullan, M. (2008). The six secrets of change. San Francisco: Josse-Bass.

Hargreaves, A. (2002). Sustainability of educational change: the role of social geographies. Journal of Educational Change, 3, 189-214. https:/ / doi.org/10.1023/A:1021218711015

Hargreaves, A. (2009). A decade of educational change and a defining moment of opportunity - an introduction. Journal of Education Change, 10, 89-100. https:/ / doi.org/10.1007/s10833-009-9103-4

Hargreaves, A. (2010). Change from without: Lessons from other countries, systems and sectors. In Hargreaves, A., Lieberman, A., Fullan, M., \& Hopkins, D. (Eds.). Second International Handbook of Educational Change (pp. 105118). London New York: Springer Dordrecht Heidelberg. https:/ / doi.org/10.1007/978-90-481-2660-6_6

Jickling, B., \& Wals, A. E. J. (2008). Globalization and environmental education: looking beyond sustainable development. Journal of Curriculum Studies, 40, 1-21. https:/ / doi.org/10.1080/00220270701684667

Levin, B. (2010). How to change 5000 schools. In A., Hargreaves, A., Lieberman, M., Fullan, \& D., Hopkins, (Eds.). Second International Handbook of Educational Change (pp. 309-322). London New York: Springer Dordrecht Heidelberg. https://doi.org/10.1007/978-90-481-2660-6_18

Levin, B., \& Fullan, M. (2008). Learning about system renewal. Educational Management, Administration and Leadership, 36, 289-303. https:// doi.org/10.1177/1741143207087778

Loughland, T., Reid, A., Walker, K., \& Petocz, O. (2003). Factors influencing young people conceptions of environment. Environmental Education Research, 9, 3-20. https:/ / doi.org/10.1080/13504620303471

Marshall, C., \& Rossman, G. B. (2014). Designing qualitative research (sixth edition) Sage.

Negev, M., Sagy, G., Garb, Y., Salzberg, A., \& Tal, A. (2008). Evaluating the environmental literacy of Israeli elementary and high school students. Journal of Environmental Education, 39, 3-20. https:/ / doi.org/10.3200/JOEE.39.2.3-20

Oplatka, I. (2005) Imposed school change and women teachers' self-renewal: a new insight on successful implementation of changes in schools, School Leadership $\mathcal{E}$ Management, 25, 171-190. https:// doi.org/10.1080/13632430500036165

Oplatka, I. (2015). The essentials of educational administration. (Third extended edition). Haifa: Pardes (Hebrew)

Raz, A. (2006). Managerial culture, workplace culture and situated curricula in organizational learning. Organization Studies, 27, 165-182. https:/ / doi.org/10.1177/0170840605056399

Rogers, E. M. (1995). Diffusion of innovations. $4^{\text {th }}$ edition, , New York: The Free Press. 
Sagy, G., \& Tal, A. (2015). Greening the Curriculum: Current Trends in Environmental Education in Israel's Public Schools. Israel Studies, 20, 57-85. https:/ / doi.org/10.2979/israelstudies.20.1.57

Sanera, M. (1998). Environmental Education: Promise and performance. Canadian Journal of Environmental, 3, 9-26.

Sarason, S. B. (1995). The school culture and processes of change. In Sarason, S. B. School change: The development of a point of view (pp. 65-84). Teacher College, Columbia University, NY and London.

Sauvé, L. (2005). Currents in environmental education: Mapping a complex and evolving pedagogical field. Canadian Journal of Environmental Education, 10, 11-37.

Spektor-Levy, O., \& Abramovich, A. (2017). From "Hesitant" to "Environmental Leader": The Influence of a Professional Development Program of the Environmental Leadership of Preschool Teachers. EURASIA Journal of Mathematics Science and Technology Education, 13(3), 649-671. https:/ / doi.org/10.12973/eurasia.2017.00637a

Stapp, W. B., Bennett, D., William B.J., Fulton, J., MacGregor, J., Nowak, P., Swan, J., Wall, R., \& Havlick, S. (1969). The concept of environmental education. The Journal of Environmental Education, 1, 30-31. https:/ / doi.org/10.1080/00139254.1969.10801479

Stevenson, R. B. (2006). Tensions and transitions in policy discourse: recontextualizing a decontextualized EE/ESD debate. Environmental Educational Research, 12, 277-290. https:/ / doi.org/10.1080/13504620600799026

Tal, T. (2004). Community-based environmental education - a case study of teacher-parent collaboration. Environmental Education Research, 10 (4), 523-543. https:/ / doi.org/10.1080/1350462042000291047

Tal, T. (2016). The gap between theory and practice in environmental education. In: I. Avisar (ed.). Challenge of Sustainability Education and Social-Environmental Responsibility (pp. 70-86). The Mofet Institute. (Hebrew)

Tal, T., \& Abramovich, A. (2013). Activity and action: Bridging environmental sciences and environmental education. Research in Science Education, 43, 1665-1687. https:/ / doi.org/10.1007/s11165-012-9327-9

Tal, T., \& Peled, E. (2017). The philosophies, contents and pedagogies of environmental education programs in 10 Israeli elementary schools. Environmental Education Research, 23, 1032-1053. https:/ / doi.org/10.1080/13504622.2016.1153047

Tal, T., Mintz, K., \& Amir, P. (2015). The program for integrating education for sustainability in the education system: whether and how the program succeeded in generating behavioural and ethical change among teaching staff and students. Research Report to the Chief Scientist, Ministry of Environmental Protection. (Hebrew)

Tilbury, D. (1995). Sustainability: defining the new focus of environmental education in the 1990S. Environmental Education Research, 1, 195-212. https:/ / doi.org/10.1080/1350462950010206

Tsevreni, I. (2011). Towards an environmental education without scientific knowledge: An attempt to create an action model based on children's experiences, emotions and perceptions about their environment. Environmental Education Research, 17, 53-67. https:/ / doi.org/10.1080/13504621003637029

Yin, R. K. (2012). Applications of case study research (3nd ed.). Thousand Oaks, CA: Sage.

\section{APPENDIX}

\section{The Semi-structured Interview Questions}

1. What is your conception of EfS? What does this term mean to you?

2. What is your opinion regarding introducing EfS into your school?

3. Do you think it was necessary to introduce this change into your school?

4. Describe the process of introducing the change to the school

5. Was there any opposition to introducing EfS into the school and, if so, how was it expressed and how did the staff cope with this opposition?

6. What do you think indicates a successful implementation process?

7. How did you evaluate the success of the change implementation?

\section{http://www.ejmste.com}

